\title{
Escritos de L. G. Kumlien e os indícios de variadas ginásticas suecas ${ }^{1}$
}

\section{Writings of L. G. Kumlien and the evidence of several Swedish gymnastics}

\author{
Iara Marina dos Anjos Bonifácio* \\ Anderson da Cunha Baía*
}

\begin{abstract}
RESUMO
A ginástica sueca, sistematizada por Pehr Henrik Ling (1776-1839) no Instituto Central de Ginástica de Estocolmo (GCI), foi divulgada pelo mundo ao menos até as últimas décadas do século XX, sobretudo, a partir do trânsito realizado por sujeitos formados no GCI. Dentre eles, podemos citar Ludvig Gideon Kumlien (1874-1934); sueco, formado no Instituto de Estocolmo, que se mudou em 1895 para Paris, na França, onde realizou diferentes ações de divulgação da ginástica de Ling, dentre elas a publicação de manuais. O que esses manuais nos revelam? Podemos afirmar que a ginástica divulgada por Kumlien é a ginástica de Ling? Ou que é a mesma ginástica que ele aprendeu no GCI? No contato com uma cultura diferente da sua de origem, Kumlien altera a ginástica que aprendeu? Assim, o presente artigo tem como objetivo compreender qual foi a ginástica divulgada por Ludvig Kumlien em seus manuais. Para dar conta disso, mobilizamos como fontes os manuais escritos por Kumlien e seus parceiros e reportagens de jornais dos países nos quais seus escritos circularam. Ao analisar os manuais de Ludvig Kumlien, observamos que a ginástica divulgada por ele em território francês foi se transformando no contato com uma nova cultura, tornando-se uma nova ginástica, diferente daquela proposta por Ling e ensinada no GCI.

Palavras-chave: Ginástica sueca. Kumlien. Educação do Corpo. Manuais. História da Educação.
\end{abstract}

1 Este trabalho foi financiado pela Coordenação de Aperfeiçoamento de Pessoal de Nível Superior (CAPES) - código de financiamento 001 - e pela Fundação de Amparo à Pesquisa do Estado de Minas Gerais (FAPEMIG).

${ }^{*}$ Universidade Federal de Minas Gerais. Belo Horizonte, Minas Gerais, Brasil. E-mail: iara_marina@hotmail.com - http://orcid.org/0000-0002-3333-0423.

** Universidade Federal de Viçosa. Viçosa, Minas Gerais, Brasil. E-mail: andersonbaia@ ufv.br - http://orcid.org/0000-0002-7363-689X 


\begin{abstract}
Swedish gymnastics, systematized by Pehr Henrik Ling (1776-1839) at the Stockholm Central Institute of Gymnastics (CIG), spread throughout the world, at least until the last decades of the 20th century, especially from the circulation of individuals trained at the CIG. Among them was Ludvig Gideon Kumlien (1874-1934), a Swedish doctor-gymnast who graduated from the Stockholm Institute, who moved in 1895 to Paris, France, where he carried out different actions to promote Ling's gymnastics, among them publishing handbooks. What do these handbooks reveal? Can we assert that the gymnastics promoted by Kumlien is Ling's gymnastics? Or that it is the same gymnastics he learned at CIG? In contact with a culture different from his own, does Kumlien alter the gymnastics he learned? Thus, this article aims to understand which gymnastics Ludvig Kumlien has promoted in his handbooks. To do so, we mobilized as sources the handbooks written by Kumlien and his partners and newspaper reports from the countries in which his writings circulated. By analyzing Ludvig Kumlien's guidebooks, we observed that the gymnastics he divulged in French territory were transformed through contact with a new culture, becoming new gymnastics, different from that proposed by Ling and taught in the CIG.
\end{abstract}

Keywords: Swedish gymnastics. Kumlien. Body Education. Handbooks. History of Education.

\title{
Introdução
}

No início do século XIX, mais precisamente em 1813, Pehr Henrik Ling (1776-1839) propôs a criação, em Estocolmo, na Suécia, de um instituto de treinamento físico para jovens através da ginástica (LINDROTH, 1979; MORENO; BAÍA, 2019; PEREIRA, [20--?]). É daí que nasce o Instituto Central de Ginástica $(\mathrm{GCI})^{2}$, o berço daquela que se tornaria internacionalmente conhecida como ginástica de Ling, ginástica sueca ou ginástica racional.

Nesse período, essa não foi a única proposição de modos de educação física, outras sistematizações nesse sentido foram elaboradas. Suas nomeações faziam referência aos territórios nos quais foram propostas. Pode-se citar, por

2 Tradução de Stockholm Central Institute of Gymnastics (GCI). Durante um tempo, o instituto tinha o nome de Royal Gymnastics Central Institute. Ao longo do texto, nos referimos ao Instituto usando a sigla GCI, como é mundialmente conhecido. 
exemplo, a ginástica francesa e a ginástica alemã. Apesar das similaridades, não se tratou de um processo homogêneo e linear, cada uma "se debruçou sobre o estudo do gesto humano a partir de uma perspectiva diferente" (QUITZAU; MORENO; BAÍA, 2019, p. 281). Em alguns momentos, houve ainda conflitos entre as diferentes proposições no sentido de afirmarem enquanto proposta mais adequada na educação dos corpos (PFISTER, 2003).

A circulação da ginástica sueca pelo mundo revela, por um lado, certo assentimento quanto a sua proposição, dita científica, de educar os corpos; por outro lado, revela um movimento deliberado por parte do GCI para que a ginástica de Ling chegasse aos diferentes territórios (principalmente após a morte de seu precursor). Sob essa ótica, Moreno e Baía $(2019$, p. 5) afirmam que "o GCI se tornou o epicentro da ginástica de Ling no mundo, divulgando o método e fazendo-o viajar além das fronteiras suecas".

Diferentes foram os autores e as autoras que empreenderam pesquisas no sentido de compreender a ginástica sueca e a sua presença nos diferentes territórios ${ }^{3}$. De modo geral, podemos afirmar que a ginástica sueca foi divulgada pelo mundo ao menos até as últimas décadas do século XX, sobretudo, a partir do trânsito de sujeitos - suecos e estrangeiros - que, em sua maioria, mantinham relação com o Instituto de Estocolmo - alunos e alunas, egressos, diretores, visitantes, entre outros. Mas circulou também por meio de manuais, criação de Institutos, congressos, entre outros modos. Em todos esses movimentos de pesquisa a ginástica proposta por Ling é referenciada ginástica racional, ginástica sueca e/ou ginástica de Ling.

Por outro lado, Quitzau, Moreno e Baía (2019), ao analisar traduções a apropriações das ginásticas sueca e alemã, indicaram caminhos importantes para se compreender a circulação das diferentes ginásticas pelo mundo. Para os autores, fazer essa análise significa pensar que o que chegou nos diferentes lugares, o que foi apropriado, será uma versão de um dos escritos sobre esses métodos ginásticos e que essas versões dependem da forma como foram transpostas para o país - manuais, traduções, sujeitos, imigrantes, entre outros. Tendo isso em vista, podemos falar de uma única ginástica de Ling? Podemos tratá-la como uma ginástica homogênea? Ao nos referir nos diferentes trabalhos sobre ginástica sueca, método sueco, ginástica de Ling, estamos dizendo da mesma coisa?

3 Nos referimos, aos trabalhos de Bolling e Yttergren (2015); Bloomfield (2005); Bagoze, Saint-Martin e Attali (2011); Sarremejane (2006); Baía, Bonifácio e Moreno (2019), Moreno e Baía (2019), entre outros. 
Interrogar a ginástica de Ling desse modo se fez possível a partir do contato com os escritos de Serge Gruzinski. Para ele, os objetos culturais - nesse caso, a ginástica sueca - não são puros nem em sua concepção, nem em sua circulação; eles sofrem influências e são transformados em meio aos diferentes espaços culturais por onde passam (GRUZINSKI, 2001). Então, como dar conta das transformações sofridas pela ginástica sueca?

Angela de Castro Gomes (1993), inspirada em Jacques Julliard, aponta que as ideias não circulam, elas mesmas, pelas ruas, mas são portadas por sujeitos e/ou grupos sociais. Explicar os sujeitos (e seus itinerários) permite-nos o entendimento acerca das mudanças culturais e políticas dos objetos culturais, em outras palavras, das ideias e das práticas sobre a ginástica sueca. Portanto, interessa-nos entender nesse processo transformativo de circulação da ginástica sueca a partir dos investimentos de um sujeito, Ludvig Gideon Kumlien (1874-1934).

Sueco, formado no GCI, Ludvig Kumlien mudou-se em 1895 para Paris, na França, onde empreendeu diferentes ações de divulgação da ginástica de Ling. Dentre elas, escreveu três manuais de ginástica: o "La Gymnastique Suédoise" (1901) - em parceria com Emile André (1859-1943); o "La Gymnastique pour tous" (1906); e o "Cour Complet d'éducation physique" (1909) - em parceria com Raoul Fabens (1862-1932). Os dois primeiros manuais circularam (traduzidos ou não) em diferentes estados do Brasil, assim como em outros países do mundo - Portugal, Espanha, Itália, Argentina (BAÍA; BONIFÁCIO; MORENO, 2019; BONIFÁCIO, 2019).

Ao investigar a trajetória de Ludvig Kumlien, nos questionamos: podemos afirmar que a ginástica divulgada por Kumlien é a ginástica de Ling? Ou que é a mesma ginástica que ele aprendeu no GCI? No contato com uma cultura diferente da sua de origem, Kumlien altera a ginástica que aprendeu?

Assim, temos como objetivo compreender qual foi a ginástica divulgada por Ludvig Kumlien em seus manuais. Tendo como hipótese que não podemos falar da ginástica sueca como algo único, homogêneo, em função dos diferentes trânsitos e mediações ocorridos no processo de circulação desse objeto cultural pelo mundo; assim, acreditamos que a ginástica divulgada Kumlien em território francês foi se transformando no contato com uma nova cultura.

Para dar conta disso, mobilizamos como fontes os manuais escritos por Kumlien e seus parceiros e reportagens de jornais dos países nos quais seus escritos circularam. Embora os manuais sejam mobilizados como fonte e não como objetos de pesquisa (GALVÃO; BATISTA, 2009), tivemos os escritos sobre a história dos impressos como lente de observação, sendo elas os estudos de Robert Darton (1990) e Roger Chartier (1991). Na análise dos jornais, ancoramos-nos em Jean-Yves Mollier (2008). Todos esses trabalhos nos possibilitaram um olhar mais refinado e atento aos diferentes processos pelos quais os impressos se constituem como tais e circulam pelos diferentes lugares. 


\section{A ginástica sueca e os manuais de Kumlien como suporte de divulgação}

O "Gymnastikens allmänna grunder" (1840) foi um dos poucos escritos deixados por Pehr Henrik Ling sobre a sua ginástica e seus princípios; todavia, o livro não se dedica à descrição dos exercícios. O primeiro capítulo diferencia-se dos demais por trazer aspectos mais filosóficos, compreendidos por Ling, a respeito do organismo humano. Os demais capítulos, apesar de também compreenderem certa dimensão filosófica, tratam mais sobre os elementos indispensáveis para a ginástica de Ling.

Para Ling, nessa obra, os elementos da ginástica caminhariam em quatro direções: a ginástica pedagógica, a ginástica militar, a ginástica médica e a ginástica estética (LING, 1840). A direção pedagógica tinha como objetivo o aprendizado do domínio sobre o próprio corpo; por outro lado, a militar, além do uso do próprio corpo, previa também o uso de elementos externos como as armas, por exemplo. A ginástica médica objetivava superar ou aliviar deficiências e desequilíbrios, sozinho ou com a ajuda de um profissional. Por fim, a ginástica estética tinha como finalidade o uso do corpo para atingir uma harmonia interior; sua prática seria capaz de unificar o corpo e a mente. Para Ling (1840), todos esses caminhos estariam interligados, e uma visão fragmentada a seu respeito dificultaria a eficiência e a eficácia dos exercícios.

O livro de Ling foi, em alguma medida, a materialização da ginástica sistematizada no trabalho diário no Instituto de Estocolmo e na convivência com seus discípulos Lars Gabriel Branting (1799-1881) e August Georgii (1808-1881) (LINDROTH, 1979; MORENO; BAÍA, 2019). Posteriormente, essa ginástica viria a ser ampliada por Hjälmar Fredrik Ling (1820-1886), filho de Ling, e por outros continuadores que atuavam no GCI (LINDROTH, 1979; PEREIRA, [20--?]).

Após a sua morte, com os continuadores, houve um grande desenvolvimento da ginástica pedagógica e da ginástica médica em detrimento da militar e da estética. Lindroth (1979) afirma que se formaram dois grupos: o ortodoxo ou "lingianismo", que defendia a base de Ling para o desenvolvimento do método; $\mathrm{e}$ o heterodoxo ou "naturalista", que acreditava que o desenvolvimento da ginástica linguiana deveria ser feito a partir de influências diversas. Além disso, houve a proposição e a incorporação de movimentos pertencentes a outras práticas que vinham ganhando espaço no cenário europeu do século XIX, como o esporte $\mathrm{e}$ a dança, por exemplo (LANGLADE, A.; LANGLADE, N., 1970; MORENO; BAÍA, 2019). A ginástica sueca foi, portanto, adaptando-se ao novo tempo, aos desafios de uma outra educação do corpo que se construía. 
Nesse processo de transformação, também a estrutura formativa do GCI sofreu alterações. Em 1887, o GCI promoveu uma reforma na qual as três ginásticas foram separadas em cursos distintos, mas relacionados, outras reformas também aconteceram anteriormente (PEREIRA, [20--?]). Assim, o percurso formativo total compreenderia três anos, sendo o primeiro destinado à ginástica militar, o segundo à ginástica pedagógica e o terceiro à ginástica médica. É nessa estrutura formativa que Ludvig Kumlien ingressou no Instituto de Estocolmo.

Observamos, portanto, que a ginástica com a qual Kumlien teve contato no GCI constituiu-se a partir de diferentes mediações e interpretações desde aquela proposta por Ling. Essa ginástica foi posta em circulação de diferentes modos, apostando, sobretudo, nas ações de divulgação de seus alunos. Dentre as diversas estratégias que podemos perceber, encontra-se a publicação de manuais ${ }^{4}$. Esse movimento também foi realizado por Kumlien.

Em Paris, Ludvig Kumlien publicou, em parceria ou não, três manuais. Sobre isso, não se pode perder de vista que a França, território no qual Kumlien escreve suas obras, regulamentou seus processos de instrução nas últimas décadas do século XIX e passou a atender gratuitamente a quase toda sua população (MOLLIER, 2008). Mollier (2008) afirma que em 1890 os manuais escolares tornaram-se de uso obrigatórios nas escolas, o que aumentou expressivamente sua produção e distribuição.

A editora Flammarion, que publicou o primeiro manual de Ludvig Kumlien em parceria com Emile André, já realizava movimentos de exportação de suas obras desde fins do século XIX (MOLLIER, 2008). E Armand Colin, o editor do terceiro manual publicado em parceria com Rauol Fabens, tinha ampla experiência com a publicação de manuais escolares (MOLLIER, 2008).

Os dois primeiros manuais de Ludvig Kumlien, "La Gymnastique Suédoise" e "La Gymnastique pour tous", foram escritos em língua francesa e, posteriormente, traduzidos para outros idiomas. Nesta sessão indica-se a circulação e os usos dos manuais escritos por Ludvig Kumlien, não se pretende dar conta desses processos, mas indicar alguns de seus vestígios. Onde o primeiro teve tradução para o espanhol, com publicações no México com o título " $L a$ gimnasia sueca: manual de gimnasia racional al alcance de todos y para todas las edades" (1909-1919); na Espanha, "La Gimnasia Sueca: Manual de Gimnasia Racional" (1919-[20--?]); e em Buenos Aires, intitulada "Gimnasia sueca al alcance de todos" (1957). O segundo manual foi traduzido para o espanhol e publicado na Espanha com o título "La gimnasia para todos" ([20--?]); 
para o italiano, e intitulado "La ginnastica per tutti: traduzione e note di um pubblico insegnante" (1911); e para o português, sob o título "Tratado Pratico de Gymnastica Sueca" (1908).

No Brasil, Vago (2002, p. 270), ao se dedicar ao ensino primário de Belo Horizonte, demonstrou a presença e os usos do "Tratado Pratico de Gymnastica Sueca" no $4^{\circ}$ Grupo Escolar. Os "exercícios de ginástica" ministrados pelas professoras de meninos e meninas tiveram como "guia" o referido manual que, por sua vez, foi apreciado e aprovado pelo Conselho Superior de Instrução Pública em 1911. Com isso, a Secretaria do Interior comprou exemplares do "Tratado" e fez com que circulasse nas Escolas Isoladas e Grupos Escolares. Localizamos registros dessas compras em 1912 na Livraria Francisco Alves em Belo Horizonte (REQUISIÇÕES, 1912).

Embora a tradução para o português tenha circulado no Brasil, o manual foi publicado em Portugal, Lisboa, e, possivelmente em função da relação entre os dois países, essa pode ter sido a via de entrada da obra em nosso país (BAÍA; BONIFÁCIO; MORENO, 2019). Se em terras brasileiras o "Tratado" esteve presente nas escolas, em Portugal ele pareceu ter conquistado relativo prestígio, uma vez que localizamos a publicação, sem autoria, da obra "Ginástica Sueca: baseada nos sistemas de Ling, Kumlien e Muller" ([20--?]) pela Empresa Literária Universal de Lisboa, Portugal. Assim, Kumlien não foi tido aqui como alguém que divulgou e ensinou a ginástica sueca, mas sim como aquele que propôs o seu próprio "sistema" de ensino.

A ginástica sueca que está presente nas obras de Kumlien circulou por diferentes territórios através de diferentes idiomas e, nesses espaços, foi mobilizada de variados modos: enquanto guias para os professores, enquanto manuais para praticantes de outras práticas físicas, ou enquanto referência para legitimação de discursos. Essa variedade de modos é indicativa de um certo prestígio da obra, sobretudo no Brasil e em Portugal, onde um manual de ginástica sueca sem autoria foi considerado baseado no "sistema de Kumlien".

Essa receptividade aos manuais também foi percebida em outros países, Flix e Betrán (2012), por exemplo, classificaram uma das obras de L. G. Kumlien como uma das cem obras que ajudaram a legitimar e institucionalizar a Educação Física nos círculos acadêmicos, sociais e profissionais na Espanha ${ }^{5}$. Assim, apesar de esses manuais terem sido publicados originalmente na França, eles circularam por outros países e podem ter, em alguma medida, conformado a educação física nesses lugares, bem como as suas compreensões acerca da ginástica sueca.

5 Sobre a circulação desses manuais em outros países, Cf. Baía, Bonifácio e Moreno (2019) e Bonifácio (2019). 
Ter em perspectiva a ação dos sujeitos na conformação de uma ginástica significa admitir que, ao analisar a sua circulação, tem-se uma versão dessa(s) ginástica(s); e essas versões dependem da forma como foram transportadas para outros lugares - manuais originais, experiência de imigrantes, traduções, ações de indivíduos, entre outros aspectos (QUITZAU; MORENO; BAÍA, 2019). Assim, eleger os manuais de Ludvig Kumlien significa compreender a ginástica sueca aos seus modos, ou seja, a ginástica aprendida por ele no GCI e a ginástica que ele conformou em sua prática cotidiana em Paris.

\section{Os manuais de Kumlien: registros de uma ginástica sueca na França}

Ludvig Kumlien e seus parceiros, conforme dito anteriormente, publicaram três manuais com os seguintes títulos: "La Gymnastique Suédoise" (1901); "La Gymnastique pour tous" (1906); e "Cour Complet d'éducation physique” (1909). Chamou-nos a atenção a alteração dos títulos ao longo do tempo, sobretudo a retirada do termo "sueca" para se referir à ginástica.

Em 1900, ano anterior à publicação do primeiro manual, Paris sediou o Congresso Internacional de Educação Física, evento no qual, segundo Sarremejane (2006), houve uma apologia à ginástica sueca. Dentre os sujeitos que fizeram a defesa da referida ginástica, o autor cita: Georges Demeny, Philippe Tissié ${ }^{7}$ e Fernand Lagrange ${ }^{8}$; todos eles sujeitos importantes no debate francês sobre a educação física. Dois anos após o referido congresso, em 1902, a École de Joinville Le Pont ${ }^{9}$, importante instituição militar francesa envolvida

6 Georges Demeny (1850-1917) nasceu em Dowai, França e mudou-se para Paris onde fundou o círculo de Ginástica Racional e, junto com E. J. Marey, fundou a estação fisiológica do Parque dos Príncipes. Organizou ainda o curso de educação física da École de Joinville Le Pont, onde foi nomeado professor de fisiologia. Em seu percurso apresentou momentos de intenso apoio ao método sueco e outros de críticas, no qual passa a defender um método francês (SOARES, 1998; SARREMEJANE, 2006).

7 Philippe Tissié (1852-1935) era médico e aprofundou seus estudos na ginástica sueca, se tornando um de seus defensores em território francês. Com isso, criou uma enorme polêmica com Georges Demeny (SOARES, 1998; BAZOGE; SAINT-MARTIN; ATTALI, 2011).

8 Fernand Lagrange (1845-1909) era médico e fisiologista. Renomado cientista que dedicou seus estudos a questões relacionadas a higiene e terapêutica e sua relação com o movimento (SOARES, 1998).

9 Fundada em 1852, a École de Gymnastique de Joinville Le Pont tinha como objetivo formar monitores capazes de ensinar a ginástica militar. Em 1872, acrescenta-se o termo "normal" ao nome, o que significou que sua formação agora tem como objetivo formar instrutores de ginástica e não apenas preparar soldados. Assim, a École de Joinville se tornou a instituição responsável pela estruturação da educação física em território francês (SARREMEJANE, 2006). 
no debate acerca do método oficial francês de educação, adota oficialmente a ginástica sueca (SARREMEJANE, 2006).

Assim, acreditamos que no momento da publicação do primeiro manual a ambiência vivenciada por Kumlien e Emile André era favorável para a nomeação de "Gymnastique Suédoise". Essa possível receptividade ao manual parece se confirmar ao passo em que ele tem uma segunda edição em 1904, e, tanto em anúncios de jornais quanto em cada de uma das edições, indica-se oito mil e dez mil impressões, respectivamente.

Entretanto, nesse mesmo ano, percebe-se uma tensão com relação à ginástica sueca. Sarremejane (2006) indica que o então presidente da França, Emile Loubet (1838-1929), criou em 1904 uma comissão interministerial, que contemplava o Ministério da Guerra e o Ministério da Instrução Pública, com o objetivo de unificar o método de educação física e criar um manual para seu ensino. Nessa comissão, Georges Demeny que outrora defendeu a ginástica sueca, passa a questioná-la e trava um embate com Emile Coste, então comandante da École de Joinville. A objeção de Georges Demeny em relação à ginástica sueca é feita também, entre outros espaços, no Congresso Internacional de Educação Física realizado em 1905 na Bélgica, em Bruxelas (DELHEYE, 2014).

Por parte de Ludvig Kumlien, observa-se que, no mesmo ano em que a segunda edição do manual é lançada, ele promove uma exibição de ginástica sueca no salão de festas do jornal Le Figaro. O evento foi noticiado com destaque em jornais franceses que afirmavam a presença de uma "audiência de elite", com nomes da medicina, da escola e do esporte da França; além disso, a exibição foi aberta com o professor Poirier, da Faculdade de Medicina de Paris (BONIFÁCIO, 2019). Acreditamos que, com ambos os movimentos, Ludvig Kumlien e seus parceiros buscavam driblar o questionamento relativo à ginástica sueca.

Em 1906, Kumlien publica sozinho o seu segundo manual "La Gymnastique pour tous"; retirando o termo suédoise e o substituindo por pour tous. Com isso, percebemos que o movimento empreendido no primeiro manual de driblar as resistências contra a ginástica sueca continuou acontecendo no manual em questão. Alterou-se o nome da obra, e utilizou-se pouco os termos gymnastique suédoise ou méthode suédoise, dando preferência para gymnastique rationnelle.

Diferentemente dos dois manuais anteriores, o "Cour complet d'éducation physique", publicado em 1909, não se dedicava especificamente à ginástica, como o próprio nome sugere; propunha, no entanto, reunir "os principais elementos de uma educação física bem compreendida e especialmente adaptada às necessidades do ensino" (FABENS; KUMLIEN, 1909, p. V). Ao invés de se opor à ginástica e aos esportes, os autores propõem aproximá-las e reuni-las de modo que uma completasse a outra. Assim, o manual organiza-se em uma 
primeira parte dedicada às "noções de higiene e fisiologia", uma segunda parte para a "ginástica educativa (ginástica sueca)" e uma terceira parte para os "jogos e os esportes escolares".

O referido manual foi publicado em parceria com Rauol Fabens, um jornalista que atuou como diretor no jornal Tous Le Sports. Além disso, foi secretário geral da Union des sociétés françaises de sports athlétiques, que posteriormente tornou-se o comitê olímpico francês nos Jogos Olímpicos de 1896 - evento idealizado por Pierre de Coubertin (1863-1937), com quem Fabens trabalhou nesse momento (BONIFÁCIO, 2019).

O movimento de aproximar a ginástica e o esporte pode ter relação com o fortalecimento do movimento esportivo em detrimento da ginástica, apesar de ambos terem coexistido na França desde fins do século XIX, momento em que o francês Pierre de Coubertin realizou diversas iniciativas para promover os Jogos Olímpicos da modernidade, que tiveram sua primeira edição em Atenas, Grécia, no ano de 1896, e, quatro anos mais tarde, em Paris, paulatinamente os esportes conquistaram espaço significativo.

Bazoge, Saint-Martin e Attali (2011) afirmam que o Congresso Internacional de Educação Física, realizado em Odense, Dinamarca, no ano de 1911, teria sido central na mudança de rumo da promoção da ginástica sueca, que vinha perdendo espaço para o esporte. Portanto, o movimento de "unir-se" ao esporte poderia ter sido uma estratégia para que a ginástica não perdesse mais espaço.

Não apenas em território francês, mas também dentro do próprio GCI, em fins do século XIX, havia propostas de se alterar a ginástica sueca com a inclusão do esporte (LINDROTH, 1979; LANGLADE, A.; LANGLADE, N., 1970). Provavelmente, Kumlien já teria percebido esse debate, uma vez que é nesse momento que ele se formava no GCI.

Diante disso, fez-se possível observar que Ludvig Kumlien alterou os títulos de seus manuais, entre outros fatores, na tentativa de driblar as resistências encontradas pela ginástica sueca no território francês. Entretanto, as alterações nesse sentido não ficaram restritas ao título.

Como mencionado, o "La Gymnastique suédoise" teve uma nova edição em 1904. Da edição de 1901 para a de 1904, mudou-se a autoria, inseriu-se mais texto e adicionou-se um novo capítulo. Ludvig Kumlien e Emile André (1901) eram tidos como autores na primeira edição; já na segunda, Emile André ([1904]) assinou sozinho a autoria da obra "de acordo com o método Kumlien". Na parte intitulada "Histoire résumée de la gymnastique", incorporou-se o seguinte trecho: 
Na França, o principal iniciador da ginástica sueca, como o Sr. Hugues Le Roux explicou tão bem, foi meu excelente professor e amigo, o $\mathrm{Sr}$. L. G. Kumlien.

E esse mestre atribui a seu ensinamento uma marca tão pessoal que foi correto, ao forçar sua modéstia, chamar esse ensinamento de "método Kumlien". Não apenas para a parte pedagógica do método sueco, mas também e especialmente para a parte médica e ortopédica, bem como para a massagem, o Sr. Kumlien rapidamente adquiriu, em Paris, uma reputação muito justificada no público e no mundo acadêmico (ANDRÉ, [1904], p. 65-66, tradução nossa).

O trecho revela a dedicação de Kumlien à ginástica pedagógica e médica, bem como sua tentativa em se inserir na "história da ginástica"; afinal, acrescenta-se sobre o seu "modo de ensinar" no tópico do manual dedicado à história da ginástica, colocando-o ao lado de Ling, Amoro ${ }^{10} \mathrm{e} \mathrm{Jahn}^{11}$, importantes expoentes da ginástica sueca, francesa e alemã, respectivamente. Assim, dizer sobre sua "marca pessoal" no ensino da ginástica no referido tópico poderia, de algum modo, ser uma tentativa de se colocar em um mesmo patamar que aqueles aos quais ele se referia anteriormente. Possivelmente, a necessidade de marcar esse "modo" tenha motivado a alteração feita no manual.

Ainda na edição de [1904], foi adicionado o capítulo "Les progrès de la gymnastique suédoise en France", uma espécie de avaliação da presença da ginástica sueca na França. Apesar das oposições, médicos, jornalistas e professores renomados afirmaram a excelência do método; inclusive, o regulamento de ginástica do exército de 1902 adotou, em partes, a ginástica sueca - "o que pode ser surpreendente é que ela ainda não foi totalmente adotada em toda a França" (ANDRÉ, [1904], p. 198).

Segundo André ([1904]), as principais causas para a resistência em relação à ginástica sueca na França eram: a rotina; o interesse de certas personalidades em utilizar a ginástica apenas como um trampolim para titulações, honrarias e votos eleitorais; a ausência de um instituto nacional de ginástica para professores, baseado em uma ginástica racional; o conhecimento insuficiente sobre a ginástica e, até mesmo, uma ignorância total a seu respeito. Porém, devido ao destaque obtido, outro entrave parece ter incomodado mais.

10 Francisco Amoros y Odeano nasceu em Valença, Espanha, em 19 de fevereiro de 1770. Foi deportado para a França em 1814 e, em 1816, naturalizou-se francês e iniciou seus movimentos para a criação dos ginásios. Amoros morreu em Paris, em 8 de agosto de 1948 (SOARES, 1998).

11 Friedrich Ludwig Jahn (1778-1852) foi um dos sujeitos envolvidos na sistematização da ginástica alemã (QUITZAU, 2014, 2015). 
Deveríamos falar de outro tipo de objeção que foi usada para impedir sua introdução mais completa na França? "É uma ginástica estrangeira", eles dizem.

É bom parecer patriótico, especialmente ser patriota, e quanto a mim, respeito muito o chauvinismo, quando é sincero; mas quando suas diferenças vão de encontro ao objetivo que propõe, é necessário, no entanto, clamar por posição!

Então, a chamada ginástica francesa é tão verdadeiramente nacional? Inclui exercícios sobre aparelhos de importação estrangeira: por exemplo, a barra é da Alemanha, onde foi chamado de reck; outros dispositivos vêm da Inglaterra, Espanha e outros países.

Mesmo se tivéssemos uma espécie de ginástica criada inteiramente na França, ele não teria menos chances de adotar um método convidado para o exterior, se for demonstrado que é mais prático, adequado para todos e bastante adequado para formar homens saudáveis e vigorosos, fortalecer a raça? (ANDRÉ, [1904], p. 201-202, tradução nossa).

O chauvinismo, termo utilizado para designar o fanatismo exacerbado, e o menosprezo pelo que é estrangeiro, assim como o patriotismo parecem ter criado tamanha resistência que "não foi dito que a teoria sueca foi introduzida no exército, nas escolas; foi dito que o "método racional' foi introduzido" (ANDRÉ, [1904], p. 202). Considerando que seu nome, que prontamente demonstrava tratar-se de uma proposta estrangeira - "sueca" -, criava tanta objeção, poderia ser uma estratégia para driblar esse problema renomeá-la, então, "método Kumlien"? Seriam somente as habilidades de ensino de Kumlien que justificariam a utilização da referida expressão? Possuir um autor francês, e não estrangeiro, poderia também contribuir para a sua aceitação?

Assim, o "La Gymnastique suédoise" deixou os primeiros rastros sobre a versão e o modo de se fazer a ginástica empreendidos por Ludvig Kumlien em território francês, ainda que ele não tivesse abandonado os princípios da ginástica sueca propostos por Ling e mediados por seus discípulos.

Diferentemente do primeiro manual, no qual os movimentos são agrupados e classificados, no "La Gymnastique pour tous" as sessões estão prontas de acordo com o sexo e a idade. Outra diferença é que são indicados somente movimentos que podem ser executados sem aparelhos, abandonando assim os exercícios realizados com corda, espaldar, cavalo e armas. Retiraram, do mesmo modo, os "movimentos de aplicação", que incluíam a prática da esgrima, natação, entre outros, permanecendo somente os jogos - para as crianças - e a marcha. Alguns movimentos com saltos também permaneceram nas séries (KUMLIEN, [1906]). 
Acreditamos que o "La Gymnastique pour tous", apesar de tentar afastar-se do seu aspecto estrangeiro, buscou, da mesma forma, driblar outra resistência encontrada na França e indicada no primeiro manual publicado por Kumlien: a rotina. Retirou-se o uso de aparelhos, determinaram-se as sessões de acordo com o público, e apresentaram-se mais sintéticos os aspectos introdutórios, que fazem menção às questões cotidianas, como o banho, a limpeza da casa, e também o papel dos pais na boa educação de seus filhos, o que compreenderia, inclusive, que praticassem juntos a ginástica para todos. Isso possibilitaria até mesmo àqueles com uma rotina sobrecarregada praticar as lições.

O "Cour complet d'éducation physique" mescla muitos elementos presentes nos dois manuais publicados por Kumlien anteriormente, tanto em relação aos conteúdos quanto aos movimentos. A grande diferença do "Cours Complet" reside no destaque dado aos jogos, e na inserção, em uma sessão de ginástica, de elementos rítmicos, cânticos e dança, no caso das mulheres. A incorporação dessas práticas bem como ter feito parte de uma obra que compreende os esportes como elementos da educação física demonstram como Kumlien gradualmente traçou estratégias para divulgar sua ginástica e, com isso, também a transformou.

Todavia, Kumlien não deixa de fazer referências à ginástica sueca, e de expressar como sua prática poderia proporcionar muitos benefícios. No "Cour complet d'éducation physique", por exemplo, dedicou-se um capítulo, intitulado "résultats de la gymnastique suédoise ou rationnelle", para mostrar os feitos e os reconhecimentos obtidos, na França, pela ginástica racional, assim como foi feito no "La Gymnastique Suédoise".

$\mathrm{Na}$ edição de 1921 do "Cour complet d'éducation physique", foram incorporados diferentes movimentos ao manual - mais de quarentas páginas muito semelhantes àqueles que já haviam sido publicados nos dois manuais anteriores, mas também alguns novos que não havíamos identificado nas outras publicações. Tanto nos novos quanto nos já publicados, percebemos a combinação de exercícios e a proposição de exercício feitos em duplas.

A possível dedicação de Kumlien na elaboração de outros movimentos ginásticos pode ter relação com o fato que, no ano da publicação da segunda edição do "Cour complet", haviam se passado aproximadamente oito anos desde que Kumlien começou a atuar como professor na École des Roches, onde permaneceu ainda por mais quatros anos. Pode ter sido a partir dessa atuação que os novos exercícios foram elaborados.

Por fim, notamos uma última alteração entre os manuais; no " $\mathrm{La}$ Gymnastique Suédoise" Kumlien e André se dedicaram, principalmente, à ginástica pedagógica e à ginástica médica - elas corresponderam a 81 e a 65 páginas, respectivamente, de um total de 226 páginas do manual, ou seja, juntas compuseram mais da metade da obra. Esse destaque dado a ambas é anunciado 
no Prefácio de Hugues Le Roux, onde afirma-se que "não insistiremos mais neste livro sobre ginástica estética. Por outro lado, falaremos muito brevemente sobre ginástica militar" (ANDRÉ, [1904], p. 69). Neste manual foram dedicadas à ginástica estética algumas linhas e à militar, pouco mais de 3 páginas.

No "La Gymnastique pour tous", as ginásticas médica, pedagógica, militar e estética somente aparecem ao final do manual, nas notas complementares. Apesar de não dizer se os exercícios propostos no manual eram de algumas dessas ginásticas, no final afirma-se que a parte pedagógica ou educativa do método sueco se aplicava a pessoas de todas as idades e de ambos os sexos. E, no "Cour Complet", não faz referência a essas divisões, mas dedicou um capítulo, intitulado "résultats de la gymnastique suédoise ou rationnelle", para mostrar os feitos e os reconhecimentos obtidos, na França, pela ginástica racional, assim como foi feito no "La Gymnastique Suédoise".

Diante do exposto, podemos perceber que ao longo de seus escritos, Ludvig Kumlien não deixa de fazer referência a Ling e/ou ao Instituto de Estocolmo; mesmo que fazê-lo pode significar resistência ao que divulga. Ainda assim, percebemos em seus escritos como que ele vai alterando a ginástica que aprendeu a partir do seu trabalho diário, das experiências, enfrentamentos. Seus manuais podem ser lidos, nesse sentido, como os registros do seu trabalho de ensino, exibição, divulgação. Assim, ainda que Ling e o Instituto tenham influenciado Ludvig Kumlien, a ginástica divulgada por ele tem a sua dimensão autoral. Essa mediação feita por Kumlien torna a ginástica que ele ensina em um bem cultural singular, um produto outro diferente daquele com o qual tomou contato em sua formação.

\section{Afinal, qual foi a ginástica sueca aos modos de Ludvig Kumlien?}

Inicialmente com uma proposta de ginástica próxima ao que acreditamos ter aprendido no Instituto de Estocolmo, Kumlien publicou o seu primeiro manual. Nele, foram apresentados diferentes elementos que permitiriam ao leitor ter uma ampla noção sobre os modos de ensinar a ginástica sueca, sobretudo a pedagógica e a médica. A segunda edição de seu primeiro manual parece ter sido o primeiro investimento em alterar essa ginástica, em função das resistências encontradas ao divulgá-la. Ainda assim, não abriu mão da nomeação "ginástica sueca", ainda que afirmasse que ela seria ensinada a partir de seu próprio método. 
A partir de então foram percebidas diferentes modificações, desde a retirada da ginástica sueca do título de suas obras até a proposição de novos exercícios, a indicação de outros modos de praticar aqueles propostos anteriormente, maior destaque dado aos jogos, e a incorporação dos jogos rítmicos e da dança. Mudou-se também o público ao qual o manual destinava-se; anteriormente preocupado com aqueles que iriam ensiná-la, ocupou-se nessa edição com os que iriam praticá-la e, novamente, retornou ao diálogo com os professores. Além disso, alterou-se a estrutura dos manuais; antes divididos assim como o GCI - entre ginástica médica, pedagógica e militar-, passaram a ser divididos em uma parte introdutória seguida dos exercícios.

Ainda que essas mudanças tenham sido feitas, sobretudo em função das resistências encontradas, Kumlien não deixou de fazer referência à ginástica sueca e a Ling. Ora de modo mais explícito, no título do manual, nos textos presentes nos livros, na mobilização dos escritos de membros do GCI; ora de forma mais contida, utilizando sinônimos como "ginástica racional", usando sujeitos franceses convencidos da ginástica sueca em suas parcerias, fazendo citações e modificando a autoria das obras.

Diante disso, percebemos como, ao longo dos anos, Ludvig Kumlien promoveu alterações na ginástica sueca que propôs divulgar e ensinar ao desembarcar em Paris. Tendo tido contato, em sua formação, com uma ginástica sueca altamente mediada pelos discípulos de Ling e seu filho, os quais deram significativo destaque ora para a ginástica médica, ora para a ginástica pedagógica, ele também deixa a sua marca nesse objeto cultural. Inicialmente reproduziu aquilo que aprendeu no GCI; após sua circulação e seu contato com as resistências e com os diferentes públicos, produziu uma outra ginástica: a sua versão da ginástica sueca.

Importante destacar que mesmo que Ludvig Kumlien tenha empreendido mudanças na ginastica divulgada por ele e que estamos chamando de ginástica sueca "aos seus modos", "à sua versão", essas alterações dialogavam com o movimento que acontecia dentro do próprio GCI, chamado de moderna ginástica sueca. Percebemos, com isso, que o Instituto de Estocolmo, ciente das críticas e das resistências que sua ginástica passou a sofrer ao longo do tempo, incorporou outras práticas ao seu método e nomeou esse processo de "modernização".

Assim, indiciamos que ao nos referir a ginástica de Ling, ginástica sueca ou ginástica racional, não podemos dizer sobre práticas homogêneas, únicas, iguais. Podemos, por outro lado, dizer que se tratam de sistematizações de base, princípios, fundamentos comuns, mas que se diferenciam, em alguma medida, com relação a sua prática; e que essas modificações podem variar de acordo com os sujeitos, os lugares ocupados por eles, experiências e repertórios acumulados por eles, entre outros aspectos. 
Reforçamos, por fim, o caráter de indiciamento das afirmações aqui construídas tendo em vista que apesar de os manuais de Ludvig Kumlien e seus parceiros serem reveladores desse processo de transformação, eles não representam as totalidades dos empreendimentos realizados pelos diferentes sujeitos que se envolveram com isso. Nesse sentido, destacamos a necessidade de que outros movimentos de pesquisa sejam realizados buscando fazer novos apontamentos relacionados a essa questão.

\section{REFERÊNCIAS}

ANDRÉ, Emile. La Gymnastique suédoise: Manuel de Gymnastique Rationnelle A la portée de tous et à tout âge d'après la méthode de L. G. Kumlien. Paris: Flammarion, [1904]. $228 \mathrm{p}$.

BAÍA, Anderson Cunha; BONIFÁCIO, Iara Marina dos Anjos; MORENO, Andrea. Tratado pratico de gymnastica sueca de L. G. Kumlien: itinerários de um manual no Brasil (1895-1933). Revista Brasileira de História da Educação, Maringá, v. 19, p. 1-23, 20 set. 2019.

BAZOGE, Natalia ; SAINT-MARTIN, Jean ; ATTALI, Michael. Promoting the Swedish method of physical education throughout France for the benefit of public health (18681954). Scandinavian Journal Of Medicine \& Science In Sports, [s.l.], v. 23, n. 2, p. 232-243, Aug. 2011.

BLOOMFIELD, Anne. Martina Bergman-Osterberg (1849-1915): creating a professional role for women in physical training. History Of Education, [s.l.], v. 34, n. 5, p. 517-534, Sept. 2005.

BOLLING, Hans; YTTERGREN, Leif. Swedish Gymnastics for Export: A Study of the Professional Careers and Lives of Swedish Female Gymnastic Directors, 1893-1933. The International Journal Of The History Of Sport, [s.l.], v. 32, n. 11-12, p. 1437-1455, Aug. 2015.

BONIFÁCIO, Iara Marina dos Anjos. Itinerários de Ludvig Gideon Kumlien e a (re) produção da ginástica sueca. 2019. 158 f. Dissertação (Mestrado em Educação) Faculdade de Educação, Universidade Federal de Minas Gerais, Belo Horizonte, 2019.

CHARTIER, Roger. O mundo como representação. Estudos Avançados, São Paulo, v. 5, n. 11, p. 173-191, jan./abr. 1991.

DARNTON, Robert. O beijo de Lamourette: mídia, cultura e revolução. São Paulo: Cia. das Letras, $1990.400 \mathrm{p}$. 
DELHEYE, Pascal. Statistics, gymnastics and the origins of sport science in Belgium (and Europe). European Journal Of Sport Science, [s.l.], v. 14, n. 7, p. 652-660, Mar. 2014.

FABENS, Raoul; KUMLIEN, Ludvig Gideon. Cours Complet d'Éducation Physique: à l'usage de la Jeunesse des Écoles. Paris: Armand Colin, 1909. 210 p.

FLIX, Xavier Torrebadella; BETRÁN, Javier Olivera. Las cien obras clave del repertorio bibliográfico español de la educación física y el deporte en su proceso de legitimación e institucionalización (1807-1938). Revista General de Información y Documentación, Madrid, v. 22, p. 119-168, jul. 2012.

GALVÃO, Ana Maria de Oliveira; BATISTA, Antônio Augusto Gomes. O Estudo dos manuais escolares e pesquisa em história. In: GALVÃO, Ana Maria de Oliveira; BATISTA, Antônio Augusto Gomes. Livros Escolares de Leitura no Brasil: Elementos para uma história. Campinas: Mercado de Letras, 2009. p. 11-40.

GOMES, Angela de Castro. Essa gente do Rio... os intelectuais cariocas e o modernismo. Estudos Históricos, Rio de Janeiro, v. 6, n. 11, p. 62-77, 1993.

GRUZINSKI, Serge. O pensamento mestiço. São Paulo: Companhia das Letras, 2001. 416 p.

KUMLIEN, Ludvig Gideon; ANDRÉ, Emile. La gymnastique suédoise: Manuel de la gymnastique rationelle a la portée de tous et à tout âge. Paris: Flammarion, [1901]. 136 p.

KUMLIEN, Ludvig Gideon. La Gymnastique pour tous. Paris: Per Lamm, [1906]. 107 p.

LANGLADE, Alberto; LANGLADE, Nelly Rey. Teoria general de la gimnasia. Buenos Aires: Editorial Stadium, 1970. 526 p.

LINDROTH, Jan. Linganism and the natural method - the problem of continuity in Swedish gymnastics. In: INTERNATIONAL CONGRESS FOR THE HISTORY OF SPORT AND PHYSICAL EDUCATION, $8^{\text {th }}, 1979$, Uppsala and Stockholm. Congress Report. Uppsala and Stockholm: SVIF, 1979. Disponível em: https://institut-schmelz. univie.ac.at/fileadmin/user_upload/i_sportwissenschaft/Diplompruefungsliteratur/ Lindroth_1979_._Lingianism_and_the_Natural_Method.pdf. Acesso em: 20 jan. 2021.

LING, Pier Henrik. Gymnastikens allmänna grunder. Upsala: Palmblad \& Comp, 1840. $239 \mathrm{p}$.

MOLLIER, Jean-Yves. O surgimento da cultura midiática na Belle Époque: a instalação de estruturas de divulgação de massa. In: MOLLIER, Jean-Yves. A leitura e seu público no mundo contemporâneo: ensaios sobre História Cultural. Belo Horizonte: Autêntica, 2008. Cap. 9, p. 175-195.

MORENO, Andrea; BAÍA, Anderson da Cunha. Do Instituto Central de Ginástica (GCI) de Estocolmo para o Brasil: Cultivo e divulgação de uma Educação Do Corpo. Educação em Revista, Belo Horizonte, v. 35, p. 1-31, 2019.

PEREIRA, Celestino Marques Ferreira. Tratado de Educação Física - Problema Pedagógico e Histórico. Lisboa: Bertrand, [20--?]. Vol I. 
PFISTER, Gertrud. Cultural confrontations: German Turnen, english gymnastics and english sport - European diversity in physical activities from a historical perspective. Culture, Sport, Society, [s.l.], v. 6, n. 1, p. 61-91, Mar. 2003.

QUITZAU, Evelise Amgarten. "A Ginástica Alemã”: Aspectos da obra de Friedrich Ludwig Jahn. Revista Brasileira de Ciências do Esporte, Florianópolis, v. 36, n. 2, p. S501-S514, abr./jun. 2014. Disponível em: http://docplayer.com.br/43233153-Aginastica-alema-aspectos-da-obra-de-friedrich-ludwig-jahn.html. Acesso em: 20 jan. 2021.

QUITZAU, Evelise Amgarten. Da 'Ginástica para a juventude' a 'A ginástica alemã': observações acerca dos primeiros manuais alemães de ginástica. Revista Brasileira de Ciencias do Esporte, Brasília, v. 37, n. 2, p. 111-118, abr. 2015.

QUITZAU, Evelise Amgarten; MORENO, Andrea; BAÍA, Anderson da Cunha. Entre traduções e apropriações: reflexões sobre a circulação e recepção dos métodos ginásticos na Alemanha e no Brasil. In: LINHALES, Meily Assbú; PUCHTA, Diogo Rodrigues; ROSA, Maria Cristina (org.). Diálogos transnacionais na história da educação fisica. Belo Horizonte: Fino Traço, 2019. p. 275-300.

REQUISIÇÕES. Ns. 1 a 176-Letra B $-1912-7^{a}$ Secção [S. J.]. In: Arquivo Público Mineiro (APM): SI 3840, 1912.

SARREMEJANE, Philippe. L'héritage de la méthode suédoise d'éducation physique en France: les conflits de méthode au sein de l'Ecole normale de gymnastique et d'escrime de Joinville au début du Xxème siècle. Paedagogica Historica, [s.l.], v. 42, n. 6, p. 817-837, déc. 2006.

SOARES, Carmen Lúcia. Imagens da educação no corpo. Campinas, SP: Autores Associados, 1998. 208 p.

VAGO, Tarcísio Mauro. Momentos iniciais do ensino de Ginástica nas Escolas Primárias de Belo Horizonte. In: VAGO, Tarcísio Mauro. Cultura Escolar, Cultivo de Corpos: Educação Physica e Gymnastica como práticas constitutivas dos corpos de crianças no ensino público primário de Belo Horizonte. Bragança Paulista: Edusf, 2002. p. 249-282.

Texto recebido em 29/09/2020.

Texto aprovado em 27/01/2021. 